\title{
Linguística Aplicada: uma identidade construida nos $\mathrm{CBLA}^{1}$
}

\author{
Applied Linguistics: an identity constructed \\ in the Brazilian Congresses of Applied \\ Linguistics
}

Renata Archanjo

Universidade Federal do Rio Grande do Norte

Natal - Rio Grande do Norte / Brasil

\begin{abstract}
RESUMO: Este artigo objetiva investigar a Linguística Aplicada (LA) como um campo de estudos produtor de conhecimento que tem sofrido muitas transformaçōes ao longo de sua trajetória de busca de uma identidade própria. Tais transformaçōes são recuperadas nas vozes de suas pesquisas ao longo dos anos. Assim, esse estudo analisa o percurso histórico da LA, com base na produção científica apresentada nos Congressos Brasileiros de Linguística Aplicada (CBLA), buscando compreender os significados revelados pelas vozes sociais que constituem o discurso sobre seu fazer científico. A análise da transformação das áreas e subáreas temáticas de estudo nesse recorte temporal apontam para a diversidade e a riqueza dos caminhos desse campo de saber que lhe configuram uma identidade própria e única.
\end{abstract}

PALAVRAS-CHAVE: Linguística Aplicada, identidade, vozes sociais.

ABSTRACT: This article aims at investigating the field of Applied Linguistics as an area which produces knowledge and which has been under many changes. These changes can be represented by the different voices of its research over the past years. Thus, this study analyzes the historical path of Applied Linguistics within the range of the Brazilian Congresses of Applied Linguistics, trying to understand the different meanings of the social voices of the scientific discourse on this field. The analyses of the evolution of these areas and subareas of study in such aforementioned congresses point towards the diversity and richness of the path of this researching field which constitute its own and unique identity.

KEYWORDS: Applied Linguistics, identity, social voices.

\footnotetext{
*archanjo@ufrnet.br

${ }^{1}$ Este artigo é um recorte da Tese de Doutorado intitulada "Vozes sociais e dimensão ética da Linguística Aplicada: a construção discursiva da área nos CBLAs”, defendida por Renata Archanjo e orientada pela Profa Dra Maria Bernadete Fernandes de Oliveira, no Programa de Pós-Graduação em Estudos da Linguagem da UFRN, em junho de 2008 .
} 


\section{Linguística Aplicada: um campo de saber povoado por vozes}

"Diga-me com quem andas e eu te direi quem és"

(Ditado popular)

"O discurso não é simplesmente aquilo que traduz as lutas ou os sistemas de dominação, mas aquilo por que, pelo que se luta, o poder do qual nos queremos apoderar"

(Michel Foucault)

A primeira epígrafe deste texto remete a uma ideia popularmente disseminada de que um bom indício de conhecimento de alguém é o conhecimento dos outros com quem ele se relaciona. Abstraindo e ampliando esse dito popular, é possível pensar também que ideias e opiniões contribuem para a formação de identidades. Pensando na construção identitária de um campo de saber não importa apenas "quem", mas, sobretudo, "o que se diz" para compreender o(s) significado(s) que assume $(\mathrm{m})$ as escolhas (teóricas e práticas) que marcam sua evolução e seu desenvolvimento. É bem provável, dessa forma, que com a prática de olhar para si e para os outros, para melhor se compreender, cresçam as chances de que o debate sobre as questôes fundamentais que regem e identificam a trajetória de um dado campo de saber promovam a compreensão de sua natureza e seu avanço.

A segunda epígrafe nos lembra que ideias e opinióes materializam-se em discursos e neles estão contidos não apenas os elementos que nos identificam e nos fazem pertencer, mas igualmente aquilo por que lutamos e que defendemos. Ideias e valores, ou melhor, pensamento valorado. Assim são os discursos e, assim, se constroem campos de saber.

Inerentes às construções de saberes estão as transformações que promovem avanços, redirecionamentos e, em alguns casos, lamentavelmente, até atrasos. Os estudos sobre a produção do conhecimento na área das Ciências Humanas gradativamente vêm sofrendo modificações decorrentes das crises dos paradigmas científicos que orientavam seu modo de produção no auge do século 19. Segundo Santos (1989, 2003, 2004), o salto qualitativo, na contemporaneidade, deu-se na busca de respostas para questôes que compreendam o que se entende por ciência humana, o discurso que ela produz e as características que a configuram, as quais devem ser orientadas, levandose em consideração a especificidade de seu objeto de estudo: o ser humano em suas relaçôes sociais. No campo dos estudos da linguagem, esses questionamentos puseram na ordem do dia discussões sobre a tradição positivista da qual a 
Linguística era subsidiária e o lugar que a Linguística Aplicada (doravante LA) ocupava nesse contexto: se produtora de saberes teóricos autônomos ou dos saberes aplicados da Linguística e de outras Ciências Humanas (CELANI, 1992).

O momento histórico de hoje ainda é palco de incertezas e questionamentos sobre os rumos do fazer científico e acadêmico. Vivemos tempos de uma modernidade de conexões rápidas, inscrita em um cronotopo (BAKHTIN, 1990; HARVEY, 1989) que faz com que tempo e espaço sejam valores fugazes e transitórios. Tempos de uma modernidade fluida composta por verdades relativas (BAUMAN, 2001), e que se defende com um clamor de que é seu poder de modificação e adaptação rápida às necessidades urgentes e cambiantes do ser humano e do mundo no qual ele vive que a faz ser adequada. Entretanto, para poder acompanhar esse tempo e produzir um conhecimento que seja algo mais do que hipóteses testadas e demonstradas no vácuo ilusório e abstrato da vida humana, é preciso pensar em um conhecimento que seja compromissado não só com questôes sociais, culturais e políticas mas também com as relaçôes sociais que constituem cada indivíduo, cada grupo, nos diferentes momentos históricos da vida. Um conhecimento que não seja totalizante, nem universalizado e padronizado em suas verdades. Um conhecimento que seja produzido em um lugar onde se abra espaço para as diferenças, para as singularidades, considerando como singular cada ser. Um conhecimento que, em se tratando do mundo da cultura, no sentido bakhtiniano, aproxime-se do mundo da vida, incluindo o ser em toda sua dimensão (BAKHTIN, 1997).

Diversos trabalhos na área dos estudos linguísticos já apontam para essas questôes, e pesquisadores como Moita Lopes (1996, 2004, 2006); Cavalcanti (2006); Rajagopalan (2003, 2006); Coracini (2003); Signorini (2006); Signorini e Cavalcanti (1998) e Geraldi (2003, 2005), no Brasil, e Pennycook (1998, 2003, 2006); Rampton (2006) e Kumaravadivelu (2006), no exterior, têm trazido contribuiçôes significativas e esclarecedoras para o debate, corroborando o sentimento de que essas são questôes importantes para a constituição de uma agenda de trabalho atual para a LA.

A discussão levantada neste artigo traz sua contribuição ao debate, na medida em que busca compreender as vozes sociais que compóem o percurso trilhado pela LA ao longo dos Congressos Brasileiros de Linguística Aplicada (doravante CBLA), seu significado e que identidade se lhe configura.

É fato que, no âmbito da produção científica, ou em qualquer ramo da ciência, são imprescindíveis os meios de divulgação do conhecimento que se produz. Assim, livros, periódicos, teses, dissertaçōes, anais de congressos e de 
simpósios, e grupos de estudo são algumas das maneiras necessárias e eficientes de divulgar, dar conhecimento e possibilitar trocas de conhecimentos produzidos. Por esses meios de divulgação temos acesso aos discursos que perpassam os diversos campos do saber, neles buscando o significado do conhecimento produzido. Um discurso sobre um dado campo de saber, qualquer que seja ele, em princípio, contém e explicita, mesmo que parcialmente, a infraestrutura tácita de ideias e conceitos que orientam, condicionam e limitam o exercício do pensamento científico (ALMEIDA, 1992). Por meio dos discursos que circulam nessas produções seria possível atribuir sentido não somente à especificidade do campo, bem como a seu passado e seu futuro, ou seja, seu passado como lugar que referencia e orienta sua prática, e seu futuro como lugar (sujeitos, grupos, sociedade) para onde esse discurso se dirige.

A opção pelo CBLA como fonte de empiria - além do fato de ser considerado o congresso máximo da área da LA - se deu pelo entendimento de que esse evento tem sido não somente um fórum privilegiado de divulgação da produção teórico-científica da LA mas, principalmente, por ser um momento em que, a cada três anos, a comunidade científica da área se questiona sobre sua prática e sobre os rumos que segue ou pretende seguir. Não podemos abstrair o fato de que a criação de um evento científico específico de uma área, tal qual um congresso, é, por natureza, uma tarefa que busca dar visibilidade ao campo do conhecimento, àquilo que ele produz, bem como aos pesquisadores que lá se apresentam, para que, periodicamente e cada vez mais, esse campo possa afirmar-se e reafirmar-se como campo de saber legítimo, fazendo convergir forças que representam um saber científico mas também político e social.

Por tal razão, esses eventos são também vivenciados pelos pesquisadores como possibilidades de expressar, em textos, discursivamente, seus próprios posicionamentos políticos, éticos e valorativos. O texto, que se configura como um conjunto de enunciados, é um acontecimento no qual múltiplas vozes sociais se encontram e se enfrentam na tarefa de constituir um discurso. Essas vozes correspondem aos pontos de vista, aos posicionamentos valorados socialmente, que por meio de seus enunciados respondem a outras vozes e com elas interagem nos múltiplos discursos que circulam na esfera do campo de conhecimento em que se entrecruzam (BAKHTIN, 1990, 2003).

Procurar ouvir as vozes sociais materializadas semioticamente significa igualmente lhes oferecer mais do que a possibilidade de uma interpretação. 
Significa lhes oferecer uma possibilidade de compreensão construída no cotejamento de pontos de vista diferentes, imbricados em uma rede de sentidos múltiplos, os quais não necessariamente precisam ser concordantes, mas participantes ativos da construção do discurso dentro do contexto social, cultural e histórico no qual ele se inscreve. Essa perspectiva de análise entende a constituição dos discursos nas relações dialógicas inerentes a todo o funcionamento da linguagem (BAKHTIN, 1990), entendidas estas como a orientação natural de todo discurso ao discurso de outrem sob a forma de uma ancoragem nos já-ditos, palavras dos outros, sentidos e juízos de valores buscados na memória discursiva, e de uma orientação para discursos ainda não ditos, outras vozes que são antecipadas e para quem são dirigidas as palavras.

É portanto nesse movimento dialógico e nessa interação com as vozes alheias que o sujeito consegue individualizar seu discurso afirmando sua singularidade e fazendo ressaltar os sentidos desejados. As relações dialógicas nada mais são do que relações de sentido, confrontadas em espaços de tensão nos quais as vozes se enfrentam. Nesse sentido, os discursos constituem-se como "inter-relações responsivas entre posições sócio-avaliativas" (FARACO, 2009). Não sendo, portanto, neutros, estão sempre remetendo a discursos anteriores e antecipando respostas futuras.

Os discursos que analisaremos a seguir recuperam a história dos oito CBLAs já realizados até então, compreendendo um recorte temporal de 21 anos, entre os anos de 1986 e 2007. Os textos que compóem a empiria da pesquisa relatada neste artigo abarcam a evolução das temáticas dos congressos, da amplificação das áreas e subáreas de estudo de forma que, as vozes sociais que perpassam os discursos sobre a natureza do conhecimento que se produz na LA apontam para a forma que sua identidade vai sendo construída e solidificada.

\section{Caminhos da LA no Brasil: o percurso do CBLA}

Em setembro de 1986, na Universidade Estadual de Campinas (Unicamp), organizado pelo Departamento de LA dessa universidade (SIGNORINI, 1998; KLEIMAN; HENRIQUES; CAVALCANTI, 1988, 1989a, 1989b) acontece a primeira edição do CBLA. Numa reunião de diversos especialistas, brasileiros e estrangeiros, de diferentes áreas dos estudos da linguagem, o congresso propôs, como objetivo comum, a discussão de questôes decorrentes da prática dos pesquisadores participantes no sentido de examinar as situaçóes-problema relevantes que cada um vivenciava em seu campo de atuação. 
Intitulado "Pesquisas e Perspectivas", o congresso sintoniza-se com o momento histórico em que se realiza o primeiro evento científico nacional da área. Esse momento revela a preocupação dominante dos pesquisadores da área que, na época, recaía na busca de caminhos para a legitimação de seu campo de estudos, na definição da natureza deste, na extensão de suas fronteiras e na descoberta de sua identidade.

Constituindo-se como a concretização de uma necessidade sentida há muito tempo pelos linguistas aplicados, o I CBLA revelou-se um encontro multidisciplinar e mutifacetado no qual os pesquisadores puderam expor uma grande variedade de trabalhos de natureza tanto teórica quanto decorrentes de experiências práticas como as questóes ligadas especificamente ao ensino. O I CBLA revelou-se igualmente um espaço para discussões sobre o estado da arte da área e suas tendências mais recentes:

[...] o congresso abriu espaço tanto para a apresentação de quadros gerais sobre o estado da arte de uma determinada área como para a apresentação de enfoques dentro das tendências mais recentes. (KLEIMAN; HENRIQUES; CAVALCANTI, 1988; 1989a; 1989b)

Composto de 30 sessões temáticas (8 conferências, 3 mesas-redondas, 6 painéis e 13 sessões de comunicação), apresenta a maioria das pesquisas com temas relacionados à língua segunda e estrangeira e língua materna. Parte das pesquisas apresentadas $(16,6 \%)$ trataram de questóes relacionadas especificamente com a LA, como objeto de investigação, e o percentual restante de trabalhos (20\%) tratou de temas ligados a questôes de tradução e educação bilíngue. Observando essa distribuição, percebemos que a maioria dos trabalhos refletia as pesquisas realizadas nas tradicionais subáreas de investigação da LA, ou seja, ensino-aprendizagem de língua estrangeira, ensino-aprendizagem de língua materna, tradução, bilinguismo e educação bilíngue, sendo estas três últimas, geralmente, agrupadas em uma só subárea.

Chama a atenção, à primeira vista, o fato de, em um congresso específico de LA, as três grandes subáreas de estudo e pesquisa mais representadas (língua segunda e estrangeira, língua materna e, tradução e educação bilíngue) serem aquelas que reproduziam, em sua organização prática, uma adequação teórica que se aliava ao olhar para o campo da LA compartilhado por grande parte dos linguistas e estudiosos da linguagem, que se buscava, justamente, nesse momento, modificar. Ou seja, apresentar a pesquisa realizada no momento, no Brasil, sob essa organização era, de certo modo, ratificar a posição 
aplicacionista, no campo prático (entenda-se a escola), das teorias linguísticas que se propunham a buscar soluções para os diversos problemas de ensino / aprendizagem encontrados no campo dos estudos da linguagem.

Entretanto, importa considerar dois aspectos: primeiramente, a organização do congresso ancorado nessas três grandes áreas refletia a organização das áreas do próprio Departamento de LA da Unicamp, promotora do evento; em segundo lugar, se a organização nessas três áreas poderia supor uma intenção conservadora, havia todo um movimento iniciado antes mesmo da realização do congresso, na sua fase de discussão e propostas (não apenas baseadas em representações de cunho teórico mas igualmente políticas) para que a concretização de um congresso representativo da área fosse mais do que a oportunidade de apresentação de pesquisas aplicadas no campo da linguagem, mas, sobretudo, a oportunidade de se apresentar os problemas de linguagem pesquisados, discutidos criticamente. Assim é também explicado pela comissão organizadora do evento:

A realização do $1^{\circ}$ Congresso Brasileiro de Linguística Aplicada [...] significou a reunião de diversos especialistas das áreas da linguagem com o objetivo comum de examinar questôes que surgem da prática, e que, pela sua própria pragmaticidade levam imbuídos em si o caráter de premência. Muitas das questôes examinadas decorrem do conjunto e da participação quotidiana em situações que levam em si o germe do problema, pois nelas estão instituídas relações de iniquidade e desequilíbrio entre os participantes [...] (KLEIMAN; HENRIQUES; CAVALCANTI, 1988; 1989a; 1989b)

Por outro lado, a decisão de abrir um espaço para agrupar trabalhos nos quais a LA, enquanto temática, revelou-se o próprio objeto de investigação, deveu-se, provavelmente, ao fato de o tema geral do congresso versar sobre a pesquisa e suas perspectivas. A abertura para discussões dessa natureza demonstra a importância de se discutir as fronteiras da LA como área de investigação e definir seus paradigmas.

As discussões apresentadas nesse congresso e no seguinte vão originar muitos dos artigos de referência consultados no Brasil, em anos subsequentes, sobre a identidade da LA: Cavalcanti (1986); Bohn (1988); Serrani (1990); Almeida Filho (1991); Kleiman (1991); Celani (1992). Também consequência desse momento de discussão inicial sobre o que se faz na LA é o fato de algumas das publicaçõos resultantes desse congresso seguirem apontando na direção de novos objetos de estudo ao mesmo tempo que permanecem as temáticas já 
consolidadas. Tomando como exemplo uma das sessões plenárias do evento a cargo da pesquisadora Stella Maris Bortoni, intitulada "Situações Dialógicas Assimétricas: implicações para o ensino", o tema tratado apresenta a questão das relações assimétricas e de poder nas interações em sala de aula. O mesmo tema é retomado em outra pesquisa, em uma sessão de comunicação proposta por Maria Izabel Magalhães e Pedro Henrique H. da Costa: "Discurso Assimétrico: a Interação Professor-Aluno". Cotejando a nova temática da interação em sala de aula, que retornará fortemente nos congressos seguintes, permanecem as pesquisas sobre produção textual, gramática textual e propostas de ensino / aprendizagem com ênfase na coesão e coerência do texto.

Outro exemplo, igualmente representativo, vem de dois momentos diferentes do congresso: uma conferência sobre a "Metodologia de Pesquisa em LA: Mudanças e Perspectivas" e a apresentação de um painel sobre "O Aprendiz de Línguas e o Microcomputador: novos horizontes educacionais". Intitulado "Pesquisas e Perspectivas", o I CBLA cumpre seu papel de apresentar a já conhecida e a nova face da LA no Brasil, abrindo as fronteiras para um reposicionamento da LA não apenas nas suas relaçôes de contiguidade com a Linguística mas também em relação aos avanços que ela pode promover em suas propostas de voltar-se para os problemas de linguagem.

O II CBLA realizou-se no período de 3 a 6 de setembro de 1989, também na Unicamp. Segundo Kleiman e Cavalcanti (1990), responsáveis pela organização dos anais desse segundo congresso, a dinâmica desse encontro apresentou um formato particular no qual os temas do congresso deram nome aos seminários, que, por sua vez, sinalizavam as áreas que seriam contempladas nos trabalhos apresentados nas sessóes de comunicação. Em comum a todos os seminários, estava o sentimento de que esse era o fórum para se levantar questôes essenciais para a consolidação, o desenvolvimento e o avanço da LA no Brasil.

Ao longo do II CBLA foram apresentadas mais de 50 comunicações, envolvendo participantes de mais de 30 instituições nacionais e internacionais (V CBLA, Caderno de Resumos, 1998). O congresso não definiu tema geral e tampouco foram definidas as áreas temáticas segundo as quais seriam organizados os seminários e as sessões de comunicação do congresso. Essa ausência de definiçãoo ou de inovação em relação ao congresso anterior deveuse, provavelmente, ao eco que ainda reverberava na área, como um todo, das discussões sobre as perspectivas para o campo da LA, ocorridas no I CBLA. Tais discussóes dominaram, por anos, o cenário da área. 
É possível perceber, porém, que, mesmo seguindo um formato diferente, esse segundo evento reuniu trabalhos que, dados os títulos dos seminários, enquadravam-se nas grandes áreas temáticas da LA (Ensinoaprendizagem de língua materna; Ensino-aprendizagem de língua estrangeira; Tradução, bilinguismo e educação bilíngue): 1- Discursividade e aprendizagem de línguas; 2- Dicionário para aprendizes e ensino de línguas; 3- Tendências no ensino de português para estrangeiros no Brasil; 4- A pesquisa em tradução, a teoria, o ensino e a prática; 5- Ensino e pesquisa em leitura; 6- Folktales, rhythm and poetry in ESL. Observando essa organização, percebemos que a LA ainda se constituía como um campo no qual a preocupação com o ensino (quer seja de língua materna ou estrangeira) e a escola era hegemônica, embora com a presença sempre inovadora de alguns trabalhos apontando para novos objetos de estudo. A temática da Interação em sala de aula reaparece e a transdisicplinaridade na LA começa a ser discutida.

O III CBLA foi realizado em 1992, em Campinas, novamente sob a organização do Departamento de LA da Unicamp. Notou-se, nesse ano, um grande aumento no número de sessóes temáticas do evento, totalizando 85 sessões. Os trabalhos dedicados a questóes de língua segunda e estrangeira e língua materna continuaram a ser maioria, tendo as duas outras subáreas uma participação mais coadjuvante.

Os registros sobre esse congresso apontam um tema que identifica as preocupações teóricas do momento sem, no entanto, registrá-lo como titulo do evento:

[...] desde 1987 estamos pensando no tema da relação entre a Linguística Aplicada e a Linguística. Aos poucos, os textos foram ganhando forma e a discussão se consolidou pela primeira vez por ocasiāo do $3^{\circ}$ Congresso Brasileiro de Linguística Aplicada, em 1992. O que ora apresentamos é o resultado dessas discussões [...] (BASTOS; BASTOS DE MATTOS, 1993).

É interessante destacar dessas palavras a alusão à problemática da relação entre a LA e a Linguística, que tem ocupado as reflexôes dos pesquisadores da área desde 1987. Essa data corresponde ao ano seguinte da realização do I CBLA quando foram discutidas questôes sobre a pesquisa em LA e suas perspectivas com a preocupação de definir o campo e suas fronteiras, especificar atribuições e caracterizar seus profissionais. $\mathrm{O}$ fato de tal preocupação ainda ecoar anos depois e por ocasião de um novo evento científico, em sua terceira edição, 
reflete não somente a importância da temática mas a percepção de que eventos científicos como congressos, simpósios, encontros e similares são momentos necessários de mise au point. Ou seja, são momentos em que se abre espaço para fazer um balanço sobre o ponto em que se encontram as reflexões e os trabalhos e o momento de verificar os avanços e /ou mudanças de rumo do campo de estudos. Tal preocupação foi evidenciada nas palavras das autoras que prefaciaram o número especial dessa revista:

Esperamos com essa coletânea de artigos, contribuir para a discussão que se dá em congressos, salas de aula e textos de periódicos. Cabe ainda observar que os autores de todos estes artigos têm formação linguística, o que reflete nossa posição de que conferir um estatuto à Linguística Aplicada não é diferenciá-la forçosamente da Linguística, mas percebê-la como uma disciplina em que há uma postura crítica frente a uma situação de uso da linguagem (BASTOS; BASTOS DE MATTOS, 1993).

Seguindo esse mesmo raciocínio, o fato de tanto o segundo quanto o terceiro CBLAs não terem definido temas centrais para seus eventos parece apontar para a compreensão de que as primeiras discussões levantadas por ocasião do primeiro congresso ainda ecoavam.

Um bom exemplo disso é a produtividade de pesquisadores da área, fruto das discussóes desse CBLA e dos anteriores que surgiram, posteriormente. De um trabalho sobre "Padrōes Interacionais" apresentado, inicialmente, nesse III CBLA, Moita Lopes publica artigos na revista Intercâmbio em 1992, um livro com M.C. Mollica em 1994 e um capítulo de livro em 2001. O mesmo caminho é trilhado pela pesquisadora A. Kleiman, discutindo os "Diálogos Truncados e Papéis Trocados: o estudo da interação no ensino de língua materna", apresentado no CBLA e publicado em seguida na revista ALFA (1993).

Exemplos de como uma voz inicial reverbera e traz continuidade na construção de um campo de saber. A temática da interação ganha definitivamente voz própria e passa a identificar uma das faces da pesquisa em LA, a pesquisa sobre ensino e sobre sala de aula, abrindo caminhos para uma mudança de foco, cada vez menos centrada em uma perspectiva de didática de línguas (materna e /ou estrangeira) e cada vez mais centrada nos atores sociais e nas condições de produção da linguagem e dos discursos.

O IV CBLA surge como um novo marco nessa história. Realizado em 1995, sempre na Unicamp, apresentou uma expansão (pelo menos numérica) 
da pesquisa científica nessa área do conhecimento. Foram reunidos nesse evento 577 participantes, representando 19 estados brasileiros e alguns países estrangeiros. Sob o tema geral "Aspectos Transdisciplinares da Linguística Aplicada”, o congresso contou com 106 sessões temáticas. A maioria dos trabalhos continuou a representar as áreas ligadas à língua materna e à língua estrangeira e segunda. Somadas a essas duas grandes subáreas já consolidadas, emergiu uma terceira subárea mista na qual se inseriram os trabalhos relacionando questões de língua materna e língua estrangeira. Uma minoria de trabalhos enfocou questôes de tradução e de educação bilíngue (KLEIMAN; CAVALCANTI; ARROJO, 1994; SIGNORINI, 1998).

Signorini (1998) descreveu o IV CBLA como um evento cuja temática geral proposta norteou as atividades desenvolvidas. Segundo sua análise, o tema fez-se presente tanto em trabalhos específicos - por exemplo, na conferência "Transdisciplinaridade na Linguística Aplicada no Brasil" e na mesa-redonda "Transdisciplinaridade em Linguística Aplicada" -, como em trabalhos (conferências, mesas-redondas e comunicaçóes) que procuraram mostrar as interfaces possíveis entre outras teorias e áreas do conhecimento com os estudos da linguagem.

A definição de um tema central para o congresso teve por objetivo orientar a apresentação dos trabalhos de pesquisa no sentido de imprimir um tom geral às discussões, destacando a importância da transdisciplinaridade não só para o campo da LA como um todo mas também para as pesquisas específicas de cada subárea que se propunham a trabalhar em uma perspectiva de intercâmbio com outras teorias significativas para os estudos da linguagem. Ao mesmo tempo, a adoção desse tema sinalizava uma tendência na direção da compreensão do que era a LA e dos caminhos para onde se dirigiam suas pesquisas. Anos mais tarde, essas reflexões compuseram um livro (SIGNORINI; CAVALCANTI, 1998), considerado referência quando se discute a temática da transdisciplinaridade no Brasil. A percepção daqueles que abordaram essa problemática nesse congresso aparece em seus trabalhos e falas, conforme nos relata Signorini (1998):

[...] a transdisciplinaridade em Linguística Aplicada é vista pela maioria dos participantes como uma prática consolidada de apropriação de conceitos e metodologia de diferentes áreas e tradições interessadas no estudo da linguagem, mas que só mais recentemente começou a ser objeto de reflexão dos pesquisadores (CELANI apud SIGNORINI, 1998, p. 177). 
De fato não há, no conjunto dos trabalhos e das discussões desenvolvidas no congresso, uma problematização sistemática do conceito de transdisciplinaridade (MOITA LOPES apud SIGNORINI, 1998, p. 177).

[...] como também não há uma problematização da necessidade de se discutir o tema (KLEIMAN apud SIGNORINI, 1998, p. 177).

Considerando que o caminho apontado para a LA não éisento de implicações, adotar essa ou aquela perspectiva, escolher trilhar esse ou aquele caminho na sua concepção de fazer ciência, não é uma atitude neutra posto que implica um posicionamento. Da mesma forma, a discussão da transdisciplinaridade para o campo da LA é como um cruzamento onde as diferentes direções remetem para uma postura ética no modo como se pensa a teoria e a prática do campo de estudos. Em uma dimensão nacional, como é a proporcionada por um congresso científico da natureza do CBLA, as escolhas dos organizadores do evento, que são também presidentes das associações de pesquisa, são escolhas (em relação à temática de destaque, por exemplo) que denotam, igualmente, a política linguística defendida por eles. Tais escolhas enquanto valoradas devem ser consideradas na dimensão da responsabilidade que as caracteriza.

O fato é que, nesse congresso, sob o grande pano de fundo do conceito de transdisciplinaridade, percebe-se um avanço considerável em relação às temáticas dos trabalhos e às perspectivas teórico-metodológicas que os sustentam. Embora ainda com um certo isolamento dos pesquisadores em seus territórios fazendo com que a transdisciplinaridade seja mais falada do que vivida, a diversidade das pesquisas vão apontando uma identidade em construção que começa pouco a pouco a ultrapassar os muros da escola e do ensino / aprendizagem de línguas, promovendo relações, se não novas, mas certamente outras, entre o estudo da linguagem em uso e nas relaçóes sociais.

Não deixa de ser importante considerar, outrossim, que, no momento em que em 1995, realizava-se na Unicamp, pela quarta vez, o CBLA, já estava fundada, no Brasil a Associação de Linguística Aplicada do Brasil (doravante $\mathrm{ALAB})$, que filiou-se à Associação Internacional de Linguística Aplicada (doravante AILA) e passou a ter uma ativa participação tanto em simpósios e congressos brasileiros e mundiais quanto nos comitês internacionais e executivos da AILA (OLIVEIRA, 2006). Não sem reconhecer todo o esforço pioneiro dos colegas da Unicamp pela realização dos quatro primeiros CBLAs, em 1997, a ALAB, cumprindo seu papel de representante da categoria em nível nacional, assume a organização do CBLA mantendo a mesma periodicidade, 
porém associando o local de realização do evento ao de atuação de seu presidente em exercício (Programas e resumos do V CBLA, 1998).

Dessa forma, entre os dias 31 de agosto e 4 de setembro de 1998, na Universidade Federal do Rio Grande do Sul, já sob a tutela da ALAB, acontece o V CBLA. Nessa quinta edição, o congresso apresentou 349 sessões de trabalho, além de 14 minicursos realizados nos dias que antecederam a abertura oficial do evento.

O V CBLA, ao contrário do anterior, não propôs um tema geral como norteador do evento, porém, todas as grandes subáreas consolidadas da pesquisa em LA no país fizeram-se representar no evento. A comissão organizadora explicitou a abrangência do encontro no que se refere às áreas de interesse ali representadas, bem como as interfaces com outras disciplinas:

Os tópicos abordados nesse encontro refletem as áreas de interesse da Linguística Aplicada, incluindo ensino e aprendizagem de língua materna, ensino e aprendizagem de línguas estrangeiras, tradução e educação bilíngue - com contribuições de outras disciplinas, tais como a linguística, sociologia, informática, estatística, antropologia, psicanálise, psicologia e ciências da educação. (V CBLA, Programas e Resumos, 1998).

É importante destacar nas palavras da comissão organizadora, a clara distinção entre a consolidada área de produção do conhecimento que é a LA nesse momento e a Linguística como área de conhecimento afim, com a qual se pode ter uma interface na busca de entendimento de questôes envolvendo a linguagem, sem haver, no entanto, o predomínio da última sobre a primeira. De certa forma, parece-nos que a quinta edição do CBLA aconteceu em um momento de relativa calmaria nas discussōes sobre os rumos da LA e sua natureza. Uma vez consolidada sua posição, parecia igualmente consolidada e aceita a ideia de que a disciplina ganhava com o intercâmbio com outras disciplinas, sem, entretanto, deixar de ser e fazer estudos linguísticos, conforme podemos compreender das palavras da comissão organizadora do evento sobre alguns dos objetivos do congresso:

Incentivar o estudo e a pesquisa, promovendo o debate de problemas relativos à linguagem e seu papel na construção do conhecimento; estimular a produção científica na área de linguística aplicada e domínios conexos. (V CBLA, Programas e Resumos, 1998). 
Quanto ao levantamento dos trabalhos apresentados nesse congresso, observou-se uma interessante presença de comunicações e mesas-redondas abordando temáticas que ultrapassavam as questões puramente de linguagem, de ensino e de aprendizagem, revelando, assim, interseçōes com outras áreas das ciências humanas, provavelmente decorrentes, entre outros fatores, do CBLA anterior que, com sua temática geral sobre a transdisciplinaridade da LA, sinalizou os rumos para a evolução da pesquisa rumo à expansão de suas fronteiras e de decisōes no âmbito da Associação Nacional de Pós-Graduação e Pesquisa em Letras e Linguística (doravante ANPOLL). ${ }^{2}$

Três anos mais tarde é a vez da sede da ALAB em Minas Gerais promover, entre os dias 7 e 11 de outubro de 2001 o VI CBLA, no campus da Universidade Federal de Minas Gerais (UFMG). Nesse ano, o evento apresentou como temática geral "A linguagem como prática social" e, mais uma vez, viu seus números ampliarem-se. Com a escolha dessa temática, o evento destaca o objetivo de apontar para "[...] um dos focos que vem se manifestando como norteador das pesquisas no século XXI” (DUTRA, D. P.; MELLO, H. R.; PAIVA, V. L. M. O., 2001).

Parece estar implícita nessa escolha a sinalização para a ampla adoção de uma concepção de linguagem que recoloca, definitivamente, o ser humano, ser de linguagem, em meio a sua história e a sua cultura. Diferentemente da concepção de linguagem dominante no século 20, para a qual o sujeito é o ser da razão, no século 21 não é apenas a razão que o define mas também suas características sociais, culturais e históricas. A linguagem, que constitui o homem, é, ao mesmo tempo, constituída nesse processo e, só cabe enquanto objeto de estudo se consideradas as práticas sociais nas quais ela acontece. Entretanto, embora sinalizando para esse foco norteador, é destacado o fato de que, no campo da LA brasileira, há, todavia, espaço para discussão e apresentação de pesquisas nas mais diversas subáreas:

O tema proposto não exclui todavia outras participações e reflexões, uma vez que a filosofia que tem permeado os congressos da ALAB é precisamente a pluralidade de perspectivas e a incorporação de novos enfoques e problemáticas. (DUTRA, D. P.; MELLO, H. R.; PAIVA, V. L. M. O., 2001).

\footnotetext{
${ }^{2}$ Em 1998, no encontro da ANPOLL em Campinas- SP, o Grupo de Trabalho (GT) de LA é desmembrado em vários novos grupos formados pelos mesmos linguistas aplicados de origem que se reagrupam em função de seus novos interesses de pesquisa (www.anpoll.org.br).
} 
A "pluralidade de perspectivas" a que se refere o texto, sugere, certamente, uma referência a toda uma discussão, já consolidada em relação ao campo da LA nos congressos anteriores, sobre a multiplicação de pesquisas com interfaces interdisciplinares, revelando, dessa forma, os novos enfoques, as novas problemáticas, ou outras concepções de linguagem, em suma, indicando uma nova face da LA no cenário brasileiro. Observamos, assim, a apresentação de 610 trabalhos nas tradicionais áreas de língua materna, língua estrangeira, tradução, educação bilíngue, mas igualmente em áreas como linguagem e prática social, processos identitários e linguagem e patologias. Nesse congresso, ainda foram oferecidos oito minicursos, bem como o lançamento do primeiro número da Revista Brasileira de Linguística Aplicada, consolidando, definitivamente, o CBLA como fórum privilegiado de divulgação das pesquisas em LA realizadas no Brasil e nos países vizinhos participantes do evento (DUTRA, D. P.; MELLO, H. R.; PAIVA, V. L. M. O., 2001).

Um passeio pelas plenárias propostas no âmbito do evento nos dá a dimensão da abertura do leque temático de trabalho com e na LA. Além da abertura com uma mesa-redonda emblemática cuja proposta foi a de discutir a "Linguística Aplicada Hoje", seguiram-se reflexões sobre as "Crenças" na aprendizagem e no ensino de línguas e na própria LA e sobre as "Identidades e as Práticas Sociais". O "Discurso, o Corpo e a Identidade" entraram em cena na inclusão temática da sexualidade e das questões de Gênero; as "Políticas Linguísticas" são incluídas nas agendas de trabalho e a "Era da Hipertecnologia na LA" demonstra definitivamente a chegada dos novos tempos.

O VII CBLA realizou-se entre os dias 10 e 14 de outubro de 2004, em São Paulo, promovido pela diretoria da ALAB, sediada, nesse período, no LAEL da Pontifícia Universidade Católica de São Paulo (PUC-SP). O tema central, "Linguística Aplicada e contemporaneidade", foi escolhido como sinalizador das diretrizes do evento no sentido de promover reflexóes críticas sobre a LA no Brasil, seus conceitos, suas práticas, suas posturas e suas metodologias, considerando o período de mudanças significativas como tem sido marcada a contemporaneidade.

Em diferentes modalidades, 669 trabalhos foram apresentados por pesquisadores brasileiros e estrangeiros. Mantendo a tradição, na semana precedente ao evento também foram oferecidos minicursos, que se mostraram inovadores quanto a seu formato, uma vez que foram ministrados na ambientação instrucional digital - on-line (FREIRE, M. M., 2004). 
A estrutura organizacional desse CBLA agrupou o conjunto de trabalhos recebidos em diversas vertentes investigativas, considerando essa classificação como representativa da produção científica da LA naquele momento: práticas docentes e processo de ensino-aprendizagem de línguas estrangeiras; interação, aprendizagem e autonomia; práticas discursivas; formadores e formação de professores; tecnologia e ensino; práticas identitárias e ideologias; metodologias de investigação; avaliação; transculturalidade; tradução e interpretação; linguagem e patologias da linguagem e políticas de linguagem.

Diferentemente do I CBLA que, em 1986, apresentou seus trabalhos organizados somente em três grandes áreas temáticas, nesse VII CBLA percebe-se um alargamento das fronteiras que, até então, têm tradicional e claramente demarcado cada subárea de estudo dentro da grande área dos estudos linguísticos. Ampliadas as fronteiras, essas também vão se tornando mais fluidas, mais permeáveis, permitindo maior contato com outras áreas e com outros conhecimentos. A tão proclamada transdisciplinaridade passa a ser experimentada em um contexto de interação dinâmica, e isso introduz novas questôes no centro das discussōes. Considerando a abertura da disciplina para novos horizontes e para novas trocas, ela nunca resulta na mesma.

No bojo dessas transformaçōes, começam a aparecer preocupaçōes explícitas, embora tímidas, em discutir questões ligadas à ideologia, à política eà linguagem. Novas identidades para a pesquisa e a produção do conhecimento na LA se formam, e o contínuo questionamento sobre que área é essa e que conhecimento é esse que produzimos revela a vitalidade que pulsa nesse campo de estudos, na contemporaneidade.

As áreas temáticas do congresso diversificam-se, seguindo a tendência dos congressos anteriores e uma especialização e diversificação já adotadas e praticadas nos cursos de pós-graduação quanto a suas áreas de interesse e pesquisa na LA. Da mesma forma, o fato de o tema geral do congresso ser definido como "Linguística Aplicada e contemporaneidade" chama a atenção para um olhar sobre o campo de estudos, considerando-se um momento histórico, social e político que assume características diferentes daquelas existentes quando do surgimento da disciplina nos anos 40 e 50 do século passado. Conforme as palavras da diretoria da ALAB à época,

A temática revelada pelo título "Linguística Aplicada e Contemporaneidade" [...] mostra-se oportuna e particularmente pertinente, na medida em que evoca um repensar e uma reflexão critica sobre conceitos, posturas, 
praticas e metodologias, (re)descrevendo-os, (re)definindo-os e (re)construindo-os à luz das mudanças profundas que têm marcado a atualidade. $\mathrm{O}$ enfoque proposto pela temática escolhida possibilita perceber o sujeito contemporâneo com as peculiaridades, abrangência e importância que lhe são intrínsecas, conceber como sua identidade é constituída e, portanto, entendê-lo enquanto ainda se estrutura como tal (FREIRE; ABRAHÃO; BARCELOS, 2005, p. 7).

Tal é a perspectiva da LA nesse momento e, portanto, da prática que ela define. Ainda segundo a diretoria da ALAB (FREIRE; ABRAHÃO; BARCELOS, 2005), a perspectiva de olhar para a LA na ótica da contemporaneidade "reafirma o caráter transdisciplinar" dela mesma. Continuam a merecer destaque, desde o congresso anterior, as temáticas que inserem as novas tecnologias no campo do ensino, na formação de professores e no trabalho com leitura e escrita, bem como as políticas linguísticas, dando continuidade a uma linha de construção identitária múltipla para a LA.

A última edição do CBLA, retratada neste artigo, realiza-se no ano de 2007, entre os dias 9 e 11 de julho, na cidade de Brasília. O VIII CBLA, que se apresenta sob o tema central "Contextos Brasileiros de pesquisa aplicada no âmbito da linguagem", continua sob a organização da ALAB, sediada, desta vez, na Universidade de Brasília (UnB). Foram apresentados 545 trabalhos mantendo a grandiosidade e a diversidade apresentada nas edições anteriores (VIII CBLA, 2007).

O tema central é bastante revelador do modo como permanece sendo entendida e vivenciada a LA no Brasil. Ao focalizar os contextos brasileiros da pesquisa, o congresso assume, primeiramente, uma compreensão de que a área apresenta uma produção própria suficientemente relevante no Brasil e, em segundo lugar, ao chamar a atenção para a pesquisa aplicada no âmbito da linguagem, rompe, definitivamente, com o conceito dos primeiros tempos sobre o fazer da LA como sendo, principalmente, a aplicação de teorias linguísticas à prática do ensino de línguas (CAVALCANTI, 1986; CELANI, 1992). Igualmente de grande importância vem a ser a alusão a uma pesquisa que tem lugar no âmbito das práticas de linguagem. Parece que, pelo menos oficialmente, é celebrado o deslocamento do polo da língua para o polo da linguagem trazendo em seu bojo múltiplas possibilidades de manifestação e de interfaces, confirmando, talvez, a construção identitária múltipla e transdisciplinar tão anteriormente anunciada.

Alguns dos temas abordados nas palestras e nas mesas-redondas, alicerces quase sempre indicadores do pensamento norteador do congresso, ratificam 
a abrangência do tema geral e mostram a diversidade de enfoque das pesquisas apresentadas. Estão presentes os clássicos trabalhos nas grandes subáreas de pesquisa em ensino e aprendizagem de línguas, de formação de professores, de leitura e de tradução, sempre necessários e base das pesquisas com e sobre a linguagem, mas igualmente trabalhos discutindo os contextos de diversidade e o transculturalismo que emergem como temáticas instigantes dos problemas de linguagem em uso, na contemporaneidade.

As políticas linguisticas públicas e a disciplinaridade da LA permanecem um assunto em pauta, embora, ironicamente, o espaço conquistado por essa última, tendo se transformado em objeto de estudo, de pesquisa, e de reflexão

crítica em outros CBLAs, nesse evento apareça diminuído. Se, numericamente, esses trabalhos não são significativos, as temáticas continuam trazendo algo de novo na construção do edifício LA, no sentido de se apresentar uma agenda efetiva para a pesquisa nesse campo de estudos.

\section{Faces identitárias da LA no Brasil}

A história aqui recuperada procura mostrar que, partindo da busca pela legitimação de uma disciplina nos primeiros anos da LA no Brasil, precedida por discussões de mesma natureza na Europa e na América do Norte, situamonos, hoje, diante de um campo de estudos consolidado e representado por uma sólida tradição de pesquisa. Com uma identidade construída por transformações, essa história também nos conta que nesse percurso fomos levados a transitar por caminhos que cotejaram diversas relações disciplinares: a LA foi, ao longo de seu percurso, multi-, pluri-, inter-, e transdisciplinar. Relações que não apenas denotam o modo como se define o objeto de estudo linguístico, mas, sobretudo, o modo como se cria inteligibilidade sobre os problemas de linguagem que emergem dos diferentes objetos de estudo e que se colocam como possibilidades de reflexão, uma vez ampliadas as fronteiras disciplinares do campo de estudos da LA.

Assumindo uma postura eminentemente crítica e política diante da identidade que se configura para a LA, na contemporaneidade, outro modo de operar, para além de toda disciplinaridade, ainda surge no cenário teóricometodológico desse campo de estudos: aquele que propóe uma LA (IN)disciplinar (MOITA LOPES, 2006). Tema e origem de muitas discussões atuais na LA, a (IN)disciplinaridade defendida por Moita Lopes (2006) sinaliza mais do que uma mudança metodológica. Sinaliza uma mudança de olhar e uma consciência de que, se móveis e cambiantes são as identidades que constituem 
os sujeitos humanos, seres de linguagem, em tempos de uma sociedade cada vez mais híbrida, instável, mutante, ao sabor das relações inventadas e reinventadas, dos avanços tecnológicos, de novos cronotopos, então, móveis e mutantes também serão as fronteiras disciplinares que nos asseguram um pertencimento teórico-metodológico quando nos dispomos a compreender esses mesmos sujeitos de linguagem e suas problemáticas. Nesse sentido, (IN)disciplina não significa a recusa de alguma disciplina, mas a aceitação de que muitas são as lentes que podem ser usadas para ver o mundo. Nenhuma delas senhora absoluta da verdade, mas cada uma delas complementar na tarefa crítica de desestabilizar, justamente, velhas e cristalizadas verdades, oferecendo novas interpretaçôes para o mundo, tarefa que deve ser o objetivo principal de todo e qualquer paradigma de pesquisa que se situe no campo das ciências humanas. A (IN)disciplina surge nesse contexto, como uma prática problematizadora de questóes que pedem interfaces interdisciplinares e posicionamentos críticos para que tanto os conceitos teóricos ou metodológicos ou as práticas cristalizadas em áreas definidas sejam desestabilizados, fazendo surgir um outro tipo de prática e de praticantes, por sua vez mais responsáveis e responsabilizados com a ética da vida e com a realidade dos sujeitos de linguagem que compóem a vida.

Não é possível, porém, ser ingênuo a ponto de não imaginar que tal cenário possa significar uma crise no modo como se pensa um campo de estudos produtor de ciência, como é o que se propõe ser a LA. A esse respeito, Souza Santos (1989) nos explica que o crescimento de uma ciência se faz com movimentos que configuram crises de crescimento e / ou crises de degenerescência, apontando para a necessidade de ampliar ou transformar conceitos e métodos ou de promover mudanças no paradigma que orienta a produção do conhecimento de um campo de saber como um todo. Seguindo esse percurso natural, a LA, conforme aponta a trajetória dos CBLAs, não somente se firmou como uma ciência própria, diferenciando-se de sua origem primeira, como ao longo desse percurso buscou definir seus parceiros. E, ao que parece, continua (re)definindo-se e questionando-se continuamente, o que lhe confere, mais do que nunca, vitalidade e aproximação com a vida e a realidade dos sujeitos de linguagem.

São as necessidades da vida e dos sujeitos que levam a essas novas percepções. São novos olhares que ampliam, modificam e transformam um campo de estudos. Nesse sentido, é sempre necessária a crítica, pois ir ao encontro da vida significa abandonar o olhar ingênuo sobre o que ela põe e 
dispõe. É necessário guardar o que é próprio da disciplina e ter indisciplina suficiente para ir além dela.

O percurso de transformação e a realidade vivida e praticada no campo de estudos da LA é revelada por meio de suas pesquisas e das vozes que ecoam nos discursos que a identificam. Seus congressos são as janelas em que essas faces se revelam e constituem não somente uma história de vida mas também uma prova irrefutável da vitalidade de uma ciência que tem na linguagem, plural, múltipla, real, sua condição de existência.

Nas novas identidades afloradas nas recentes transformações desse campo de estudos e confirmadas nas trajetórias de seus congressos, também identificamos a ética que perpassa todas as atividades desse campo. $\mathrm{O}$ agir é um ato ético (BAKHTIN, 1993, 1997). Assim a pesquisa, como um agir do sujeito, também é um ato ético. $O$ discurso que traduz esse agir, emergindo nas vozes sociais que o configuram, é a fonte em que vamos buscar o significado e a valoração do agir que identifica a ética de cada um.

Nesse sentido, a identidade de um campo de estudos que revela, cada vez mais, uma preocupação com questôes implicadas na vida do sujeito de linguagem, não somente da sua realidade linguística mas também das condiçōes, dos contextos, dos valores, dos conceitos e pré-conceitos que estão imbricados em sua vida, é uma identidade que revela uma preocupação ética. É no movimento de trazer a produção do conhecimento (o mundo da cultura) para significar no mundo da vida, e não para significar em um teoreticismo abstrato, cujo significado só faz sentido dentro dos muros da teoria que o reveste, que o saber se torna ético.

\section{Referências}

ALMEIDA, M. C. O Saber Antropológico: complexidades, objetivaçôes, desordens, incertezas. 1992. Tese (Doutorado em Antropologia) - Pontifícia Universidade Católica de São Paulo, São Paulo, 1992.

ALMEIDA FILHO, J. C. P. Maneiras de Compreender Linguística Aplicada. Letras (Linguística Aplicada). UFSM, n. 2, p. 7-14, jul.-dez. 1991.

ARCHANJO, R. Vozes sociais e dimensão ética da Linguística Aplicada: a construção discursiva da área nos CBLAs. 2008. 213 f. Tese (Doutorado em Estudos da Linguagem) - Universidade Federal do Rio Grande do Norte, Natal, 2008.

BAKHTIN, M. Estética da criação verbal. Trad. Paulo Bezerra. 4. ed. São Paulo: Martins Fontes, 2003. 476p. 
BAKHTIN, M. Hacia una filosofia del acto ético. De los borradores: y otros escritos. Rubi (Barcelona): Anthropos; San Juan: Universidad de Puerto Rico, 1997. 249p.

BAKHTIN, M. Para uma Filosofia do Ato. Tradução inédita de Carlos Alberto Faraco e Cristóvão Tezza de BAKHTIN, Mikhail. Toward a Philosophy of the Act. Austin: University of Texas Press, 1993. 92p.

BAKHTIN, M. Formas do tempo e de cronotopo no romance. Ensaios de poética histórica. In: BAKHTIN, M. Questôes de literatura e de estética. 2. ed. São Paulo: Hucitec, 1990. p. 211-362.

BASTOS, L. K. X.; BASTOS DE MATTOS, M. A. A Linguística Aplicada e a Linguística. Trabalhos em Linguistica Aplicada, Campinas, n. 22, p. 7-24, jul.dez. 1993.

BAUMAN, Z. Modernidade líquida. Trad. Plínio Dentzien. Rio de Janeiro: Jorge Zahar, 2001. 258p.

BOHN, H. I. Linguística Aplicada. In: BOHN, H.I.; VANDRESEN, P. (Org.). Tópicos de Linguística Aplicada. O Ensino de Línguas Estrangeiras. Florianópolis: Ed. da UFSC, 1988.

CAVAlCANTI, M. C. A propósito de Linguística Aplicada. Trabalhos em Linguística Aplicada. Campinas, v. 7, n. 2, p. 5-12, 1986.

CAVALCANTI, M. C. Um olhar metateórico e metametodológico em pesquisa em linguística aplicada: implicações éticas e políticas. In: MOITA LOPES, L. P. (Org.). Por uma Linguística Indisciplinar. São Paulo: Parábola Editorial, 2006. p. 233-252.

CELANI, M. A. A. Afinal o que é Linguística Aplicada? In: PASCHOAL, M. S. Z. de; CELANI, M. A. A. Linguística aplicada: da aplicação da linguística à linguística transdisciplinar. São Paulo: EDUC, 1992. p. 15-23.

CELANI, M. A. A. Transdisciplinaridade na Linguística Aplicada no Brasil. In: SIGNORINI, I.; CAVALCANTI, M. C. (Org.). Linguística Aplicada e Transdisciplinaridade. Questôes e Perspectivas. Campinas: Mercado de Letras, 1998. p. 129-142.

CONGRESSO BRASILEIRO DE LINGUISTICA APLICADA - CBLA, 5 , 1998, Porto Alegre. Programa e Resumos. Porto Alegre: UFRGS; ALAB, 1998. $269 \mathrm{p}$.

CONGRESSO BRASILEIRO DE LINGUISTICA APLICADA - CBLA, 8 , 2007, Brasília. Caderno de Resumos. Brasília: ALAB, 2007. 372p.

CORACINI, M. J.; BERTOLDO, E. S. (Org.). O desejo da teoria e a contingência da prática. Campinas: Mercado de Letras, 2003. 342p. 
DUTRA, D. P.; MELlO, H. R.; PAIVA, V. L. M. O. (Org.). Congresso Brasileiro de Linguística Aplicada - A linguagem como prática social, 6, 2001, Belo Horizonte. Programa e Resumos. Belo Horizonte: UFMG / ALAB, 2001. 262p.

FARACO, C. A. Linguagem \& diálogo: as ideias linguísticas do Círculo de Bakhtin. São Paulo: Parábola, 2009. v. 1, 165p.

FREIRE, M. M. (Org.). Congresso Brasileiro de Linguística Aplicada Linguística Aplicada e contemporaneidade, 7, 2004, São Paulo. Programa e Resumos. São Paulo: LAEL - PUC/SP / ALAB, 2004. 218p.

FOUCAULT, M. A ordem do discurso. 12. ed. São Paulo: Ediçōes Loyola, 2005.

FREIRE, Maximina M.; ABRAHÃO, Maria Helena V.; BARCELOS, Ana Maria F. (Org.). Linguistica Aplicada e contemporaneidade. São Paulo: ALAB; Campinas: Pontes Editores, 2005. p. 11-23

GERALDI, J. W. A diferença identifica. A desigualdade deforma: percursos bakhtininanos de construção da ética através da estética. In: FREITAS, M. T.; JOBIM E SOUZA, S.; KRAMER, S. (Org.). Ciências Humanas e Pesquisa: Leituras de Mikhail Bakhtin. São Paulo: Cortez, 2003. p. 39-56.

GERALDI, J. W. Pesquisa em Linguagem na Contemporaneidade. In: XI SETA. IEL, Campinas, SP, 2005.

HARVEY, D. Condição pós-moderna. São Paulo: Edições Loyola, 1989. p. $187-$ 276.

KLEIMAN, A. B. Introdução. E um início: a pesquisa sobre interação e aprendizagem. Trabalhos em Linguistica Aplicada. Campinas, n. 18, p. 5-14, jul/ dez. 1991.

KLEIMAN, A. B.; HENRIQUES, E. R.; CAVALCANTI, M. C. Anais do I Congresso Brasileiro de Linguística Aplicada. v. I - Língua Materna. Trabalhos em Linguística Aplicada. Campinas: IEL/UNICAMP, n. 12. 1988.

KLEIMAN, A. B.; HENRIQUES, E. R.; CAVALCANTI, M. C. Anais do I Congresso Brasileiro de Linguística Aplicada. v. II - Língua Estrangeira. Trabalhos em Linguistica Aplicada. Campinas: IEL/UNICAMP, n. 13. 1989a.

KLEIMAN, A. B.; HENRIQUES, E. R.; CAVALCANTI, M. C. Anais do I Congresso Brasileiro de Linguística Aplicada. v. III - Tradução, Bilinguismo e Educação Bilingue. Trabalhos em Linguistica Aplicada. Campinas: IEL/ UNICAMP, n. 14. 1989b.

KLEIMAN, A. B.; CAVALCANTI, M. C. Anais do II Congresso Brasileiro de Linguística Aplicada. Trabalhos em Linguística Aplicada. Campinas: IEL/ UNICAMP, n. 16. 1990. 
KLEIMAN, A. B.; CAVALCANTI, M. C.; ARROJO, R. IV Congresso Brasileiro de Linguística Aplicada. Trabalhos em Linguistica Aplicada. Campinas: IEL/UNICAMP, n. 24. 1994.

KUMARAVADIVELU, B. A Linguística Aplicada na Era da Globalização. In: MOITA LOPES, L. P. (Org.). Por uma Linguistica Indisciplinar. São Paulo: Parábola Editorial, 2006. p. 129-148.

MOITA LOPES, L. P. Contextos Institucionais em L.A.: novos rumos. Intercâmbio. São Paulo: PUC/LAEL, v.5, p. 3-14. 1996.

MOITA LOPES, L. P. A transdisciplinaridade é possível e Linguística Aplicada? In: SIGNORINI, I.; CAVALCANTI, M. C. (Org.). Linguistica Aplicada e Transdisciplinaridade: questóes e perspectivas. Campinas, SP: Mercado de Letras, 1998. p. 113-128.

MOITA LOPES, L. P. Uma linguística aplicada mestiça e ideológica: interrogando o campo como linguista aplicado. In: MOITA LOPES, L. P. (Org.). Por uma Linguistica Indisciplinar. São Paulo: Parábola Editorial 2006. 279p.

OLIVEIRA, M. B. F. A linguística aplicada hoje e o ensino de língua materna. Conferência. Currais Novos / RN, 2006.

PENNYCOOK, A. A Linguística Aplicada dos anos 90: em defesa de uma abordagem crítica. In: SIGNORINI, I.; CAVALCANTI, M. C. (Org.). Linguistica Aplicada e Transdisciplinaridade: questôes e perspectivas. Campinas, SP: Mercado de Letras, 1998. p. 23-49.

PENNYCOOK, A. Linguística Aplicada Pós-Ocidental. In: CORACINI, M. J.; BERTOLDO, E. S. (Org.). O desejo da teoria e a contingência da prática. Campinas: Mercado de Letras, 2003. p. 21-59.

PENNYCOOK, A. Uma Linguística Aplicada Transgressiva. In: MOITA LOPES, L. P. (Org.). Por uma Linguistica Indisciplinar. São Paulo: Parábola Editorial, 2006. p. 67-84.

RAJAGOPALAN, K. Por uma Linguistica Crítica: linguagem, identidade e a questão ética. São Paulo: Parábola Editorial, 2003. 143p.

RAJAGOPALAN, K. Repensar o papel da Linguística Aplicada. In: MOITA LOPES, L. P. (Org.). Por uma Linguistica Indisciplinar. São Paulo: Parábola Editorial, 2006. p.149-168.

RAMPTON, B. Retuning in applied linguistics. International Journal of Applied Linguistics, v. 7, n. 1, p. 3-25. 1997.

RAMPTON, B. Continuidade e mudança nas visōes de sociedade emLinguítica Aplicada. In: MOITA LOPES, L. P. (Org.). Por uma Linguistica Indisciplinar. São Paulo: Parábola Editorial 2006. p. 109-128. 
SANTOS, B. S. Introdução a uma ciência pós-moderna. Rio de Janeiro: Graal, 1989. 176p.

SANTOS, B. S. Um discurso sobre as ciências. São Paulo: Cortez, 2003. 92p.

SANTOS, B. S. (Org.). Conhecimento prudente para uma vida decente. Um discurso sobre a ciência revisitado. São Paulo: Cortez, 2004a. 821p.

SERRANI, Silvana M. Transdisciplinariedade e discurso em Linguística Aplicada. Trabalhos em Linguistica Aplicada. Campinas, n. 16, p. 39-45, jul/dez. 1990.

SIGNORINI, I. Do residual ao múltiplo e ao complexo: o objeto da pesquisa em Linguística Aplicada. In: SIGNORINI, I.; CAVALCANTI, M. C. (Org.). Linguistica Aplicada e transdisciplinaridade: questôes e perspectivas. Campinas, SP: Mercado de Letras, 1998. p. 99-110.

SIGNORINI, I.; CAVALCANTI, M. C. (Org.). Linguística Aplicada e Transdisciplinaridade: questóes e perspectivas. Campinas, SP: Mercado de Letras, 1998. 215p.

SIGNORINI, I. A questão da língua legítima na sociedade democrática: um desafio para a Linguística Aplicada contemporânea. In: MOITA LOPES, L. P. (Org.). Por uma Linguistica Indisciplinar. São Paulo: Parábola Editorial 2006. p. $169-190$.

Recebido em 20/02/2010. Aprovado em 15/01/2011. 